\title{
ARTICLE
}

\section{ACUTE LYMPHOBLASTIC LEUKEMIA}

\section{Dual targeting of MTOR as a novel therapeutic approach for high-risk B-cell acute lymphoblastic leukemia}

\author{
Zheng Ge $\mathbb{1}^{1,2} \cdot$ Chunhua Song ${ }^{1,3} \cdot$ Yali Ding ${ }^{1} \cdot$ Bi-Hua Tan ${ }^{1} \cdot$ Dhimant Desai ${ }^{1} \cdot$ Arati Sharma $^{1}$ • \\ Raghavendra Gowda ${ }^{1}$. Feng Yue ${ }^{1}$. Suming Huang $\mathbb{D}^{1}$ - Vladimir Spiegelman ${ }^{1}$ - Jonathon L. Payne $\mathbb{D}^{1,4}$. \\ Mark E. Reeves ${ }^{4}$ - Soumya Iyer ${ }^{1}$ - Pavan Kumar Dhanyamraju ${ }^{1} \cdot$ Yuka Imamura ${ }^{1}$ - Daniel Bogush ${ }^{1}$. \\ Yevgeniya Bamme $\mathbb{D}^{1} \cdot$ Yiping Yang $^{3} \cdot$ Mario Soliman $^{1} \cdot$ Shriya Kane $^{1} \cdot$ Elanora Dovat $^{1} \cdot$ Joseph Schramm $^{1}$.

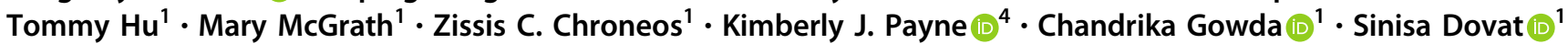

Received: 26 September 2020 / Revised: 28 November 2020 / Accepted: 7 January 2021 / Published online: 2 February 2021

(c) The Author(s) 2021. This article is published with open access

\begin{abstract}
Children of Hispanic/Latino ancestry have increased incidence of high-risk B-cell acute lymphoblastic leukemia (HR B-ALL) with poor prognosis. This leukemia is characterized by a single-copy deletion of the IKZFI (IKAROS) tumor suppressor and increased activation of the PI3K/AKT/mTOR pathway. This identifies mTOR as an attractive therapeutic target in HR B-ALL. Here, we report that IKAROS represses MTOR transcription and IKAROS' ability to repress MTOR in leukemia is impaired by oncogenic CK2 kinase. Treatment with the CK2 inhibitor, CX-4945, enhances IKAROS activity as a repressor of MTOR, resulting in reduced expression of MTOR in HR B-ALL. Thus, we designed a novel therapeutic approach that implements dual targeting of mTOR: direct inhibition of the mTOR protein (with rapamycin), in combination with IKAROS-mediated transcriptional repression of the MTOR gene (using the CK2 inhibitor, CX-4945). Combination treatment with rapamycin and CX-4945 shows synergistic therapeutic effects in vitro and in patient-derived xenografts from Hispanic/Latino children with HR B-ALL. These data suggest that such therapy has the potential to reduce the health disparity in HR B-ALL among Hispanic/ Latino children. The dual targeting of oncogene transcription, combined with inhibition of the corresponding oncoprotein provides a paradigm for a novel precision medicine approach for treating hematological malignancies.
\end{abstract}

These authors contributed equally: Zheng Ge, Chunhua Song, Yali Ding

Supplementary information The online version contains supplementary material available at https://doi.org/10.1038/s41375021-01132-5.

$\triangle$ Chandrika Gowda

cgowda2@pennstatehealth.psu.edu

$\triangle$ Sinisa Dovat

sdovat@pennstatehealth.psu.edu

1 Pennsylvania State University College of Medicine, Hershey, PA 17033, USA

2 Zhongda Hospital, Medical School of Southeast University Nanjing, 210009 Nanjing, China

3 Ohio State University College of Medicine, Columbus, $\mathrm{OH} 43210$, USA

4 Loma Linda University College of Medicine, Loma Linda, CA 92350, USA

\section{Introduction}

Children with Hispanic/Latino ancestry have a higher incidence of acute lymphoblastic leukemia (ALL) and increased mortality from this disease [1]. The incidence of a specific subtype of high-risk B-ALL, characterized by an IGH/CRLF2 translocation, is highly increased in these children [2]. The translocation of the cytokine receptor-like factor 2 (CRLF2) gene results in increased expression of CRLF2 [3] and increased activation of its downstream signaling pathways [4]. CRLF2 is an upstream regulator of the PI3K/AKT/mTOR pathway and increased $C R L F 2$ expression leads to upregulation of this pathway [4]. Aberrant activation of the PI3K/ AKT/mTOR pathway is frequently detected in high-risk BALL and is associated with chemoresistance and poor prognosis [5, 6]. mTOR (mammalian Target of Rapamycin) is a serine/threonine kinase that directly regulates cellular proliferation and metabolism [7, 8]. Increased expression and activation of mTOR are associated with poor outcomes in ALL $[9,10]$. 
The IKZFI gene encodes IKAROS, which acts as a tumor suppressor in B-ALL [11-13]. IKAROS regulates gene expression via chromatin remodeling [14-18]. Reduced IKAROS activity due to deletion and/or inactivating mutations often results in high-risk B-ALL, which is associated with resistance to chemotherapy [19-31]. We have shown that the deletion of one $I K Z F 1$ allele is highly increased in B-ALL of Hispanic/Latino children. Further, we found that the combination of $I K Z F 1$ deletion and CRLF2 translocation is 15 times more common in this group than in the non-Hispanic/Latino pediatric patient population ${ }^{\text {COMPANION PAPER }}$. Subtypes of B-ALL with CRLF2 translocation and IKZFI deletion frequently give rise to Ph-like ALL [32]. Treatment of Ph-like ALL is challenging, thus B-ALL with CRLF2 overexpression and/ or $I K Z F 1$ deletion are often resistant to conventional treatment, and have an increased incidence of relapse and poor prognosis [31-33]. Novel targeted treatment is essential to reduce health disparities in Hispanic/Latino children with B-ALL.

Here, we report that IKAROS represses transcription of the $M T O R$ gene via chromatin remodeling. In high-risk B-ALL, IKAROS's ability to regulate $M T O R$ expression is abolished due to deletion of one $I K Z F 1$ allele and phosphorylation of the IKAROS protein by oncogenic Casein Kinase II (CK2). Inhibition of CK2 restores IKAROS-mediated transcriptional repression of MTOR in B-ALL. Combination treatment with CX-4945 and the direct mTOR inhibitor, rapamycin, shows synergistic therapeutic effects in vitro and in preclinical models of high-risk B-ALL from Hispanic/Latino children. These data lay the groundwork for clinical testing of combination therapy that targets both MTOR gene expression (via restoration of IKAROS activity by CK2 inhibition), as well as direct inhibition of the mTOR protein (with rapamycin) in high-risk B-ALL. Such therapy has the potential to reduce the health disparity experienced by Hispanic/Latino children with high-risk B-ALL.

\section{Materials, subjects and methods}

\section{Cell culture and reagents}

The Nalm6, 697 (EU-3), and HEK-293T (293T) cell lines have been described previously $[34,35]$. Primary human BALL cells were cultured as described previously [36, 37].

\section{High-risk B-ALL patient-derived xenograft models}

$2 \times 10^{6}$ cells per mouse were transplanted intravenously into 4-week-old female NOD.Cg-Ragl $1^{\text {tmlMom }} I l 2 \mathrm{rg}^{\text {tml } 1 \mathrm{Wjl}} / \mathrm{SzJ}$ (NRG) mice. Following engraftment, mice received vehicle only, CX-4945 (daily via gavage at $100 \mathrm{mg} / \mathrm{kg} /$ day), rapamycin (4 mg/kg intraperitoneal injection [IP] 5 days/ week) or combination treatment with CX-4945 (100 mg/kg/ day) and rapamycin ( $4 \mathrm{mg} / \mathrm{kg}$ IP 5 days/week) until death of the first animal in experiment (3-5 weeks). Following the treatment period, total living cells in the bone marrow (BM) and spleen of mice were determined by hemocytometer count, and were used in combination with flow cytometry to calculate leukemia burden as reported previously [37].

ChIP-Seq data are accessible on NCI Gene Expression Omnibus (GEO) under accession numbers GSE58825, GSE44218, and GSE141572

Additional details regarding reagents, animal studies, patient samples, experimental methods, and data accession are found in the online Supplemental Materials.

\section{Results}

\section{IKAROS represses transcription of MTOR}

Analysis of global DNA binding showed that IKAROS binds to the MTOR promoter region in B-ALL cell lines and primary cells from patients (Figs. 1a-b, and S1a-b). IKAROS binding at the MTOR promoter was determined by a quantitative chromatin immunoprecipitation (qChIP) assay of primary B-ALL cells (Fig. 1c), and B-ALL cell lines (Fig. S2). IKAROS binding at the MTOR promoter was not detected in primary B-ALL with a deletion of one IKZF1 allele, Fig. 1c, (Patient 1) or in 293T cells, which do not express IKAROS (Fig. S2).

The direct effect of IKAROS binding at the MTOR promoter was studied using a transient co-transfection assay with the MTOR promoter, that spans $-1 \mathrm{~kb}$ to $+500 \mathrm{bp}$ relative to the $M T O R$ transcription start site (TSS). Cotransfection of $I K Z F 1$ resulted in decreased luciferase activity, suggesting that IKAROS binding to the MTOR promoter represses transcription (Fig. 1d).

\section{IKAROS represses transcription of MTOR in B-ALL via chromatin remodeling}

We tested the effect of increased IKAROS expression on MTOR transcription in Nalm6 and 697 B-ALL cells. Increased IKAROS expression following retroviral transduction resulted in increased IKAROS occupancy at the MTOR promoter (Fig. S3a-b), and reduced expression of MTOR as measured by qRT-PCR and Western blot (Fig. 2a).

Targeting IKAROS with shRNA in Nalm6 and 697 cell lines resulted in a loss of IKAROS binding at the MTOR promoter (Fig. S3c-d), and increased expression of MTOR, as measured by qRT-PCR and Western blot, (Fig. 2b). 
Overexpression of IKAROS resulted in increased $\mathrm{H} 3 \mathrm{~K} 27 \mathrm{me}^{3}$ and a loss of H3K9ac (Fig. 2c) at the MTOR promoter. Targeting IKZFI with shRNA resulted in increased $\mathrm{H} 3 \mathrm{~K} 9 \mathrm{ac}$ and $\mathrm{H} 3 \mathrm{~K} 4 \mathrm{me}^{3}$ at the MTOR promoter (Fig. 2d).

Taken together, these data provide evidence that IKAROS acts as a transcriptional repressor of MTOR in BALL via formation of repressive chromatin at the MTOR promoter.
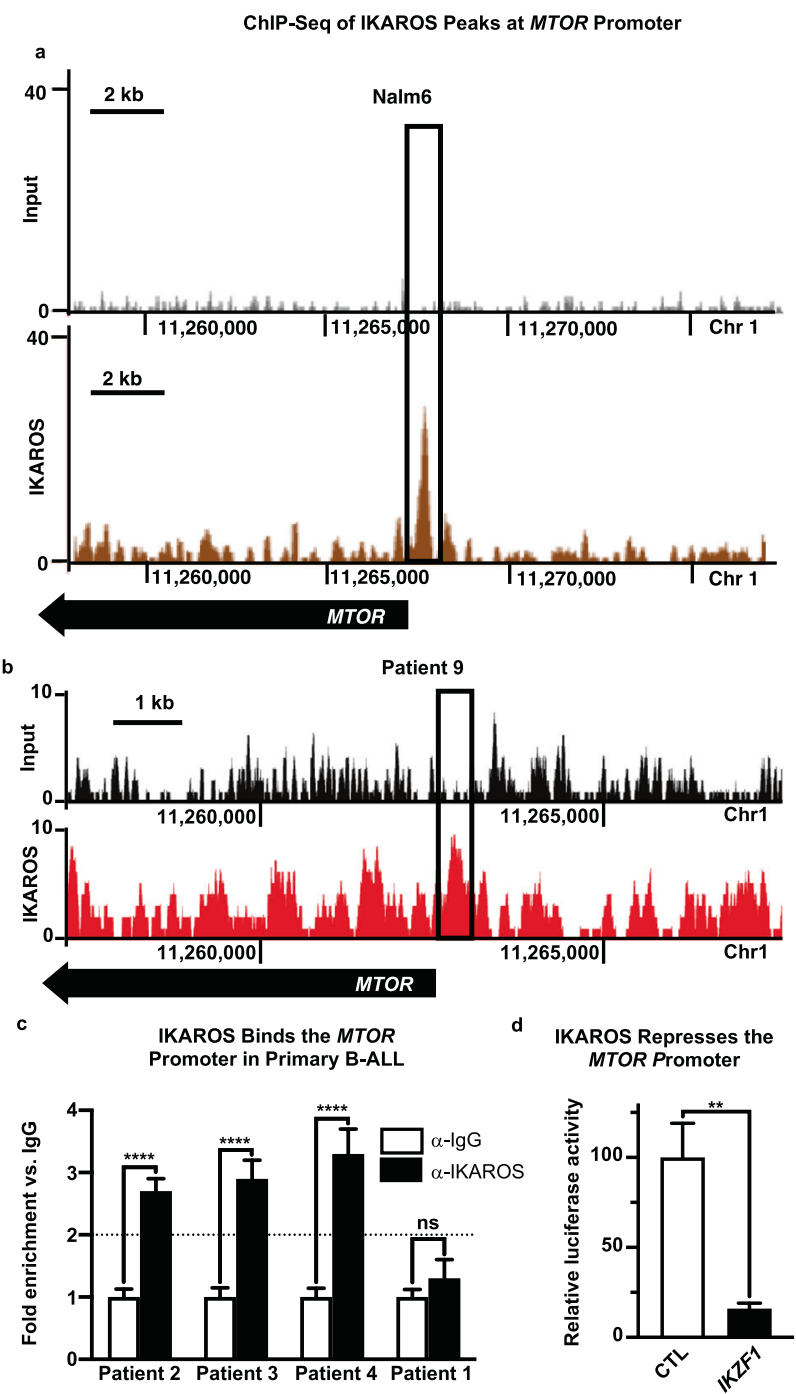

Fig. 1 IKAROS binds to the promoter of the MTOR gene and suppresses mTOR expression. a IKAROS binding sites were identified by ChIP-Seq at the MTOR promoter in the (a) Nalm6 B-ALL cell lines and in a (b) B-ALL patient sample. c qChIP data confirming IKAROS binding at the MTOR promoter in primary B-ALL cells with wildtype IKZFI (Patients 2-4) but not in IKZFI haploinsufficiency (Patient 1). d Activity of the MTOR promoter ( $-1 \mathrm{~kb}$ to $+500 \mathrm{bp}$ ) was assessed by luciferase reporter assay following transfection with IKZF1 plasmids or control vector in $293 \mathrm{~T}$ cells.
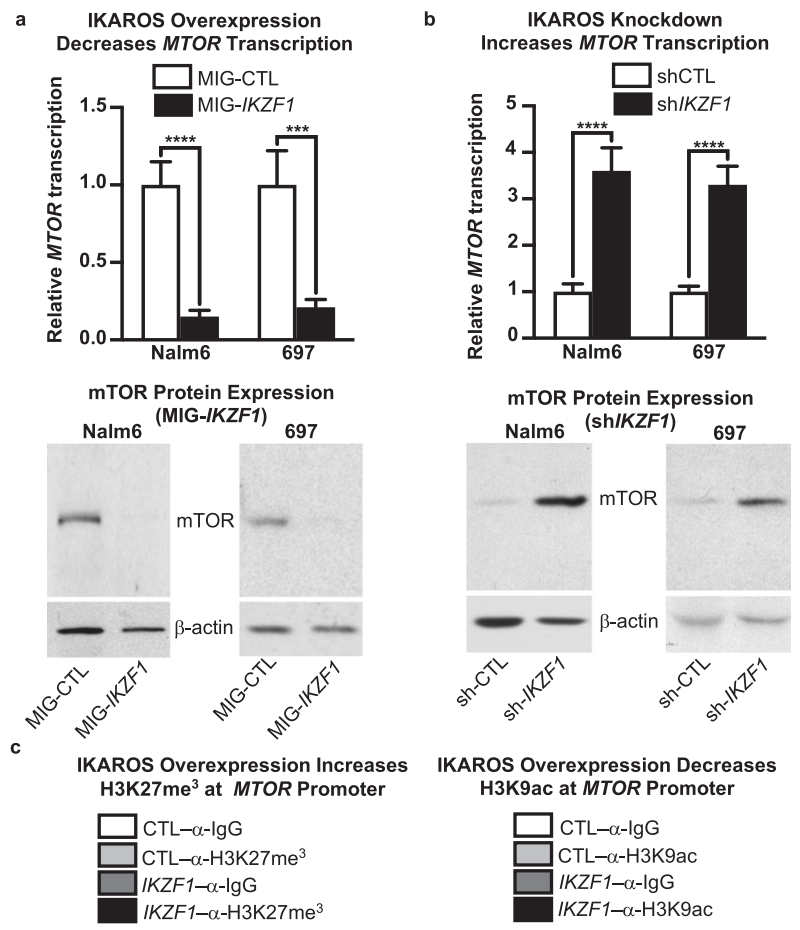

IKAROS Overexpression Decreases $\mathrm{H} 3 \mathrm{~K} 9 \mathrm{ac}$ at MTOR Promoter

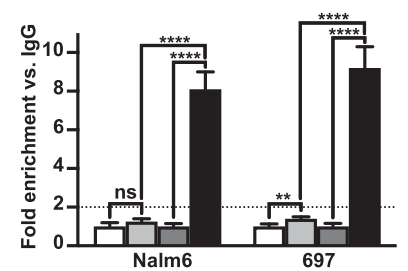

d IKAROS Knockdown Increases H3K9ac at MTOR Promoter
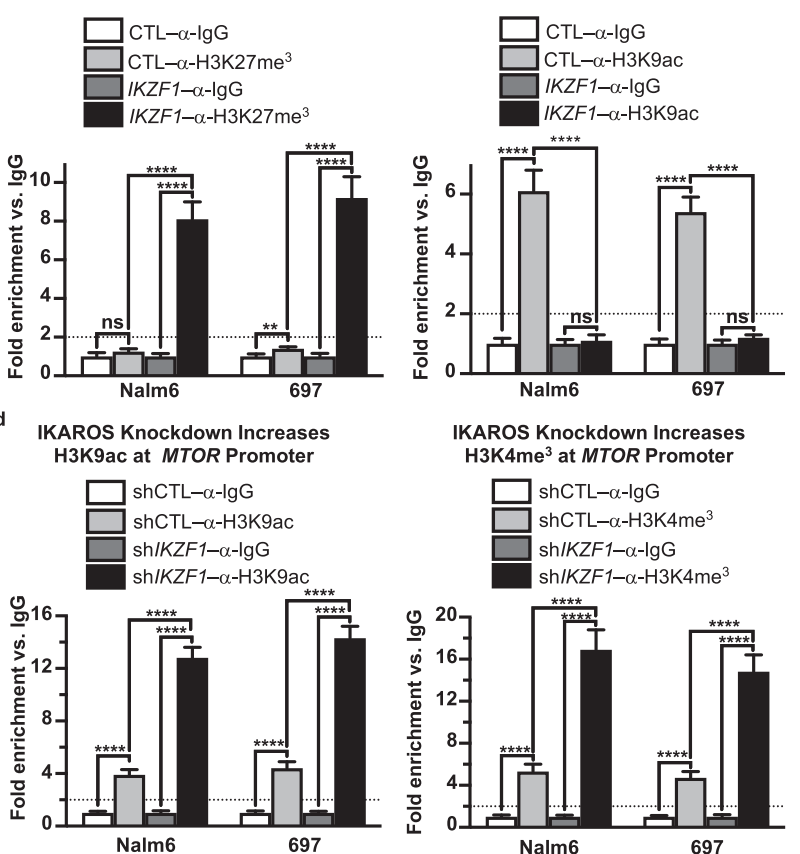

IKAROS Knockdown Increases H3K4me ${ }^{3}$ at MTOR Promoter

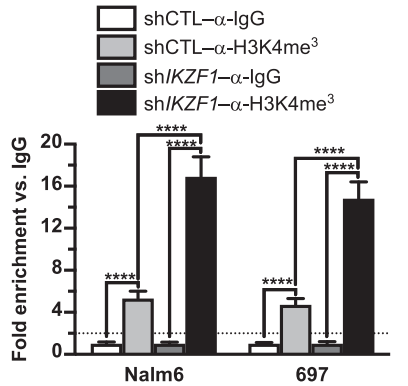

Fig. 2 IKAROS represses transcription of MTOR in B-ALL via chromatin remodeling. a Nalm6 and 697 B-ALL cell lines were transduced to express IKZF1 (MIG-IKZF1) or with empty vector (MIG-CTL). Relative expression of MTOR was assessed by qRT-PCR (top panel) and by Western blot (bottom panel). b Nalm6 and 697 BALL cell lines were treated with IKZF1 shRNA (shIKZF1) or control shRNA (shCTL). The relative expression of MTOR was assessed by qRT-PCR (top panel) and by Western blot (bottom panel). c qChIP data showing the presence of $\mathrm{H} 3 \mathrm{~K} 27 \mathrm{me}^{3}$ and $\mathrm{H} 3 \mathrm{~K} 9 \mathrm{ac}$ marks at the MTOR promoter in Nalm6 and 697 B-ALL cells with IKAROS overexpression. d qChIP data showing H3K9ac and $\mathrm{H} 3 \mathrm{~K} 4 \mathrm{me}^{3}$ marks at the MTOR promoter in Nalm6 and 697 B-ALL cells with $I K Z F 1$ shRNA knockdown. Cells were treated for 3 days for the experiments in $(\mathbf{a}-\mathbf{d})$; graphed data are the mean $\pm \mathrm{SD}$ of combined values from three independent experiments. $* * * p<0.001$, $* * * * p<0.0001$. 
Fig. 3 CK2 inhibits IKAROSmediated repression of MTOR. a-b Effect of CK $2 \alpha$ knockdown on mRNA levels of (a) MTOR. Effect of pharmacological inhibition of CK2 (with CX4945) on MTOR expression in (b-c) cell lines and in (d) patients 2-4. e Effect of CK2 $\alpha$ overexpression (MIG-

$C S N K 2 A 1)$ and vector only control (MIG-CTL) on MTOR expression. $\mathbf{f}$ Effect of IKAROS knockdown $(\operatorname{sh} I K Z F 1)$ or scramble shRNA control (shCTL) on changes in MTOR gene expression induced by CK2 inhibition with CX-4945. Cells were treated with $5 \mu \mathrm{M}$ CX-4945 for 2 days in (b-d) and (f). Patients 2 and 3 are Hispanic/Latino, patient 4 is non-Hispanic/Latino. Graphed data are the mean \pm SD of combined values from three independent experiments.

$* * * p<0.001, * * * * p<0.0001$. a

CK2 $\alpha$ Knockdown Decreases MTOR Transcription in Cell Lines

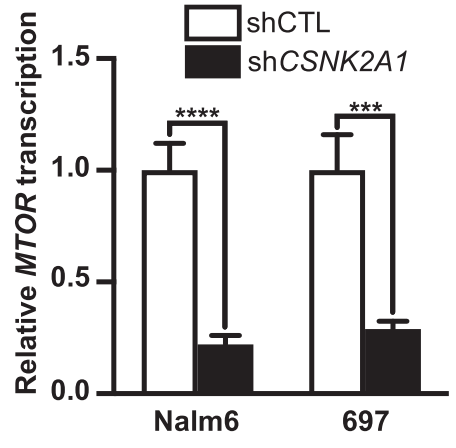

c

CX-4945 Decreases mTOR Protein Levels

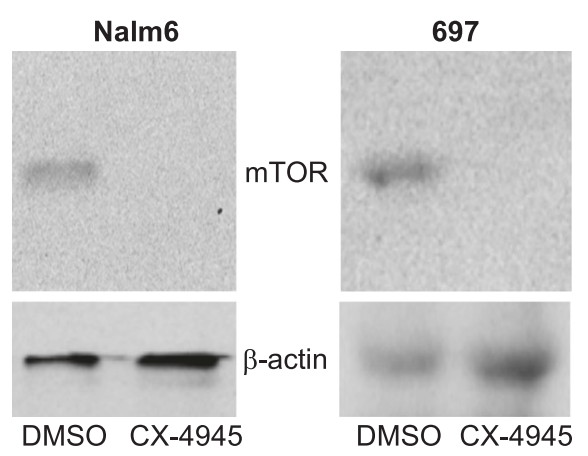

e

CK2 $\alpha$ Overexpression Increases MTOR Transcription

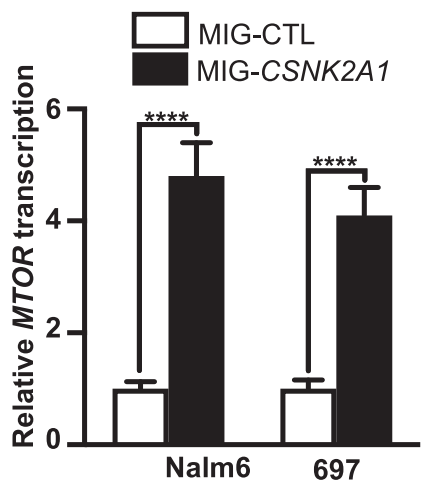

b

CX-4945 Decreases MTOR Transcription in Cell Lines

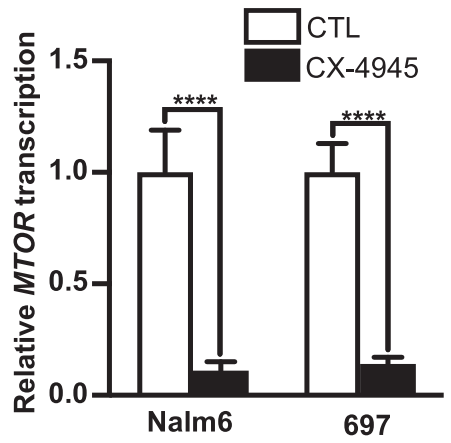

d

CX-4945 Decreases MTOR Transcription in Primary B-ALL

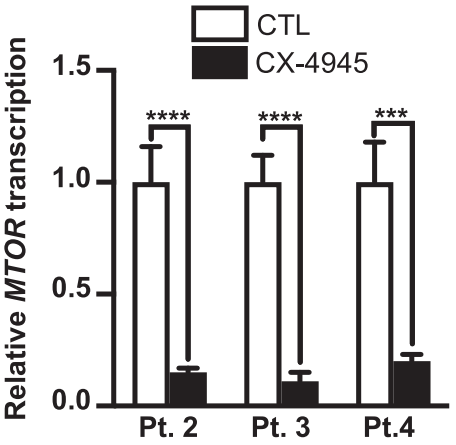

f CX-4945 Repression of MTOR is IKAROS-Dependent

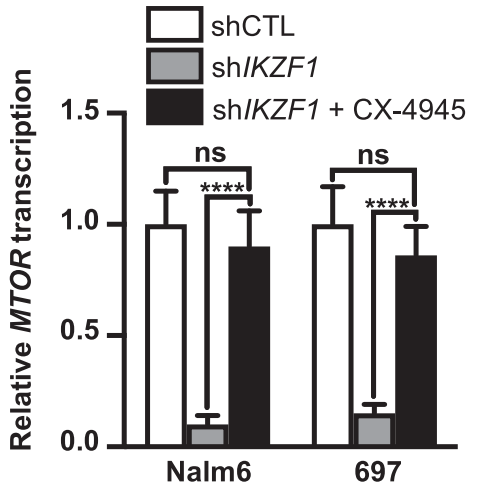

\section{CK2 inhibits IKAROS-mediated repression of MTOR}

In leukemia, direct phosphorylation by CK2 reduces IKAROS DNA-binding affinity and its activity as a transcriptional regulator $[38,39]$. We tested whether CK2 regulates IKAROS' ability to control MTOR transcription in B-ALL. Molecular inhibition of $C K 2$ with shRNA targeting the catalytic subunit of the CK2 holoenzyme, $C K 2 \alpha$, (Fig. S4a), resulted in repression of the MTOR gene (Fig. 3a), along with increased binding of IKAROS at the MTOR promoter (Fig. S4b). A similar effect was achieved with pharmacological inhibition of $\mathrm{CK} 2$ with specific inhibitors, CX-4945 (Fig. 3b-c, Fig. S5-S6a) and TBB (Fig. S7a-b) in B-ALL cells. Treatment with CX-4945 resulted in increased $\mathrm{H} 3 \mathrm{~K} 27 \mathrm{me}^{3}$ and a loss of $\mathrm{H} 3 \mathrm{~K} 9 \mathrm{ac}$ at the MTOR promoter (Fig. S8). Since the PI3K/AKT/mTOR pathway is often upregulated in B-ALL in Hispanic/Latino children $[33,40]$, we tested the effect of CK2 inhibition on IKAROS's ability to regulate MTOR transcription in primary B-ALL cells from pediatric patients that were Hispanic/Latino (patients 2 and 3), as well as non-Hispanic/ Latino (patient 4). CK2 inhibition with CX-4945 increased IKAROS binding at the MTOR promoter (Fig. S6b) and severely repressed MTOR transcription (Fig. 3d). 


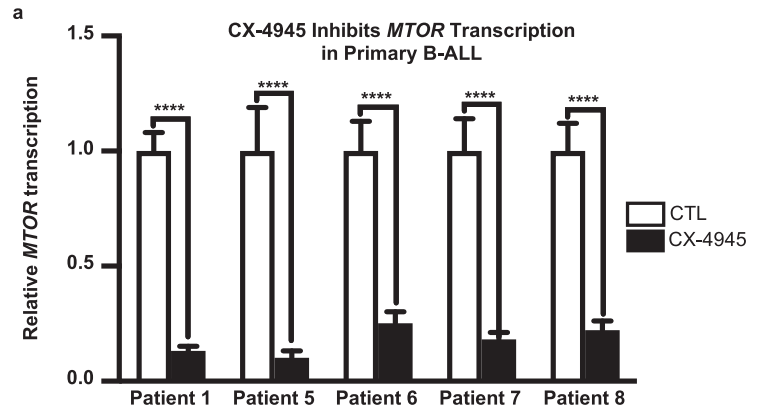

b
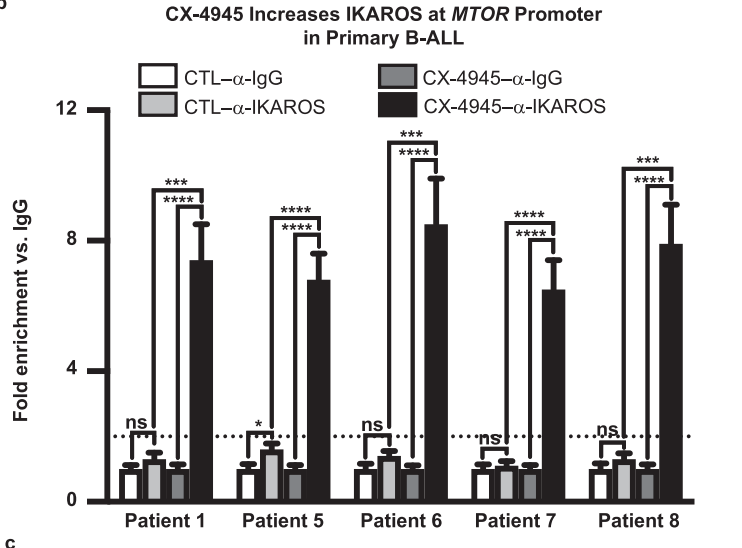

c

CX-4945 Increases H3K27 $\mathrm{me}^{3}$ at MTOR Promoter in Primary B-ALL

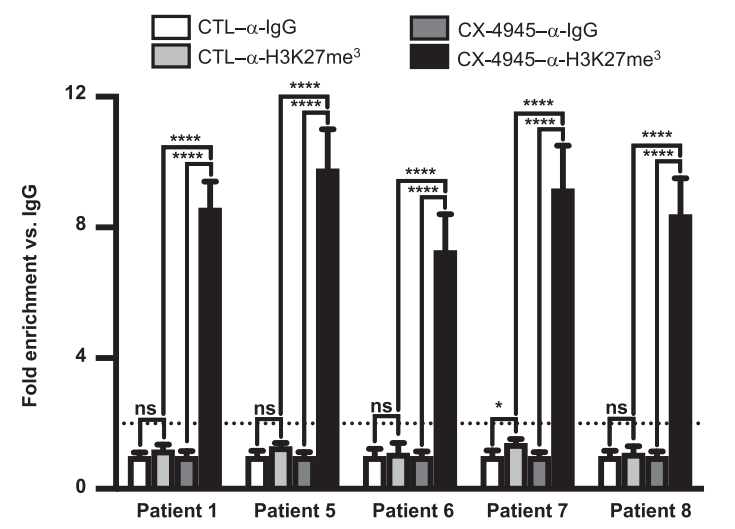

d

CX-4945 Decreases H3K9ac at MTOR Promoter in Primary B-ALL

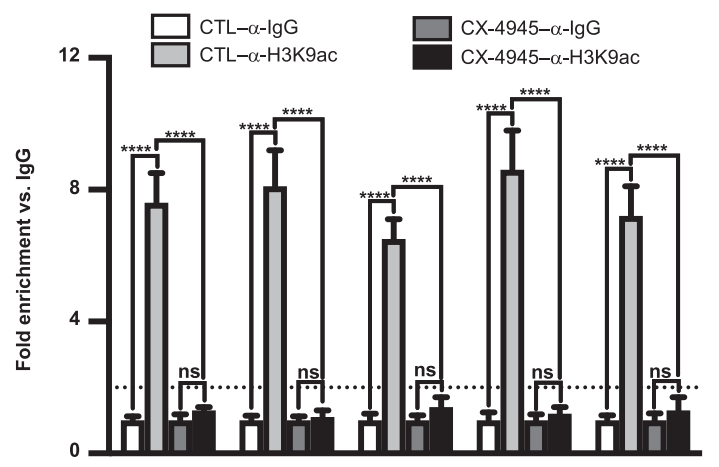

Overexpression of $C K 2 \alpha$ in B-ALL cells results in increased transcription of the MTOR gene (Fig. 3e), and a loss of IKAROS binding at the MTOR promoter (Fig. S9). We
Fig. 4 CK2 inhibition restores IKAROS' ability to regulate MTOR expression in primary high-risk B-ALL with deletion of one IKZF1 allele. a MTOR mRNA level was measured by qRT-PCR in primary high-risk B-ALL samples following treatment with $10 \mu \mathrm{M}$ CK2 inhibitor (CX-4945) for 2 days as compared to untreated (CTL) cells. b-d qChIP analysis of (b) IKAROS (c) H3K27me $\mathrm{H}^{3}$, and (d) $\mathrm{H} 3 \mathrm{~K} 9 \mathrm{ac}$ at the MTOR promoter. Untreated cells are (white and light gray bars) compared to and CX-4945-treated primary high-risk B-ALL (dark gray and black bars). Patients 1, 5, and 6 are Hispanic/Latino. Graphed data are the mean $\pm \mathrm{SD}$ of combined values from three independent experiments. ${ }^{*} p<0.05, * * * p<0.001, * * * * \mathrm{p}<0.0001$.

tested whether IKAROS is the critical protein through which CK2 regulates MTOR expression. Treatment of B-ALL cells with the CK2 inhibitor, CX-4945, along with scrambled shRNA, resulted in reduced transcription of the MTOR gene; however, IKZFI knockdown with shRNA was able to rescue CX-4945-mediated repression of MTOR in both cell lines (Fig. 3f). These data show that IKAROS activity is essential for the repression of the MTOR gene following CK2 inhibition and suggest that CK2 inhibitors repress MTOR expression by enhancing the function of IKAROS.

Together, these data demonstrate that in B-ALL the expression of MTOR is regulated by the CK2-IKAROS signaling axis, and that alteration in activity of CK2 and/or IKAROS results in changes in MTOR expression.

\section{CK2 inhibition restores IKAROS' ability to regulate MTOR expression in high-risk leukemia cells from Hispanic/Latino children}

Hispanic/Latino children have increased incidence of BALL with deletion of one IKZFI allele, along with an upregulation of the PI3K/AKT/mTOR pathway and a Phlike gene expression profile [24, 41]. We tested whether IKZF1 haploinsufficiency affects IKAROS's ability to regulate $M T O R$ expression and whether CK2 inhibition can regulate the expression of $M T O R$ in primary B-ALL cells with deletion of one IKZF1 allele, including three samples from Hispanic/Latino patients (Table S1). CK2 inhibition with CX-4945 resulted in transcriptional repression of the MTOR gene in B-ALL cells from all five B-ALL patients (Fig. 4a). In the B-ALL patient samples that lack one IKZFI allele, the IKAROS protein does not bind the MTOR promoter (Fig. 4b, light gray bars vs. white bars). CK2 inhibition with CX-4945, restores IKAROS binding in these cells (Fig. 4b, black vs. dark gray bars), and results in the formation of repressive chromatin, characterized by $\mathrm{H} 3 \mathrm{~K} 27 \mathrm{me}^{3}$ enrichment (Fig. 4c), and loss of H3K9ac (Fig. 4d) at the MTOR promoter.

Together, these data demonstrate that CK2 inhibition in high-risk B-ALL cells with the deletion of one IKZFI allele, including those from Hispanic/Latino children, restores 

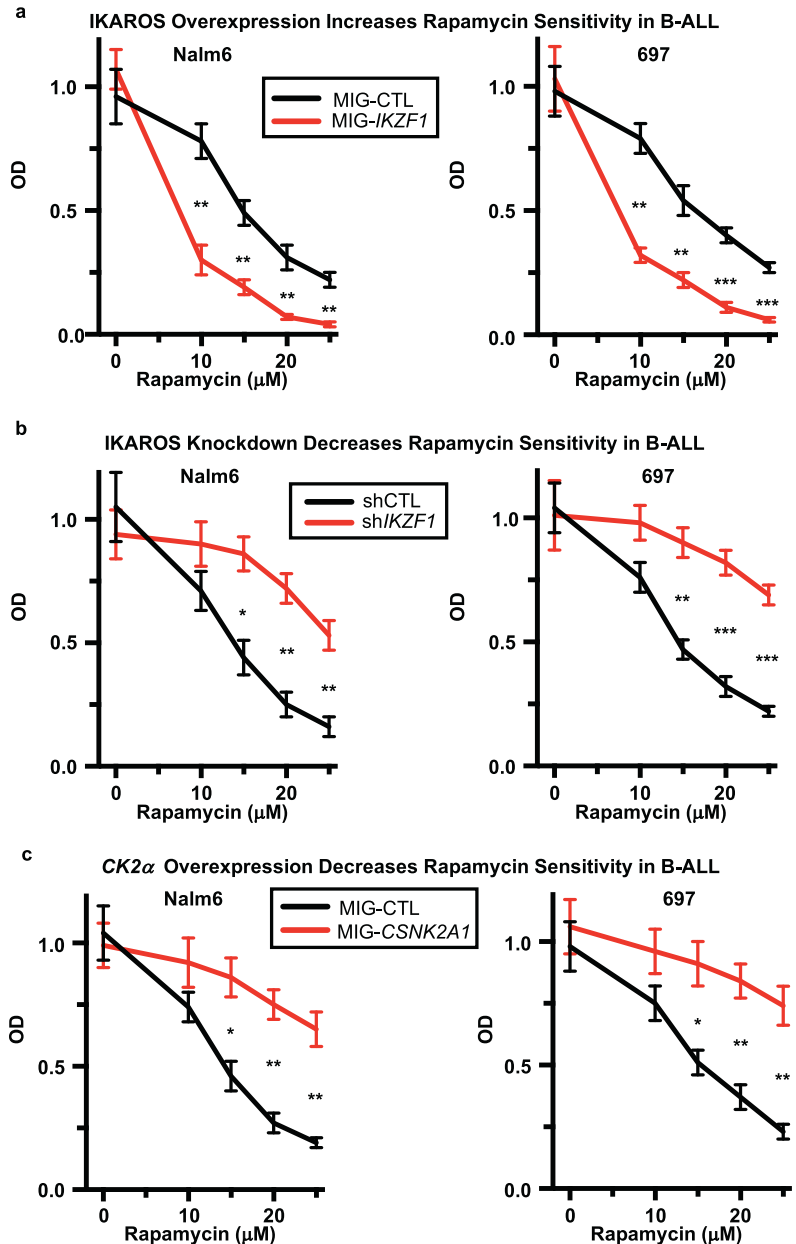

d

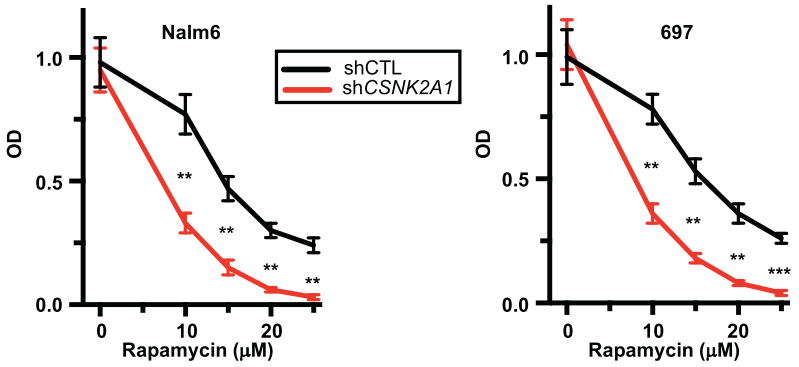

Fig. 5 IKAROS and CK2 regulate sensitivity to rapamycin in BALL cells. a B-ALL cells, retrovirally transduced with IKZF1 (MIG$I K Z F 1)$ or a control vector (MIG-CTL), were FACS-sorted and treated for 3 days with indicated doses of rapamycin and assayed using the WST-1 cell proliferation assay. b B-ALL cells, transduced with lentiviral IKZFI shRNA (shIKZF1) or scramble shRNA control (shCTL), were FACS-sorted and treated for 3 days with indicated doses of rapamycin. c-d B-ALL cells with retroviral: (c) $\mathrm{CK} 2 \alpha$ overexpression (MIG-CSNK2A1) or vector only control (MIG-CTL); or (d) lentiviral CK2 $\alpha$ shRNA (shCSNK2A1) or scramble shRNA control (shCTL), were FACS-sorted and treated with indicated doses of rapamycin for 3 days then evaluated by WST-1 proliferation assay. Graphed data are the mean \pm SD of combined values from three independent experiments. $* p<0.05$, $* * p<0.01$, $* * * p<0.001$.
IKAROS' ability to bind DNA, induces formation of repressive chromatin at the $M T O R$ promoter, and represses transcription of $M T O R$.

\section{IKAROS and CK2 regulate sensitivity of B-ALL to rapamycin}

Increased mTOR expression and/or activation are associated with poor outcomes in ALL $[9,10]$. Therapeutic effects of the mTOR inhibitor, rapamycin, have been tested in clinical trials $[8,42-45]$. Since our data demonstrated that IKAROS represses expression of the MTOR gene, we tested the effect of IKAROS expression on sensitivity to rapamycin treatment in B-ALL. IKZFI overexpression resulted in increased sensitivity to rapamycin (Fig. 5a). Knockdown of IKZFI with shRNA resulted in reduced sensitivity to rapamycin (Fig. 5b). These results show that IKAROS expression directly correlates with sensitivity to treatment with rapamycin.

Because CK2 inhibition reduces MTOR transcription via IKAROS, we tested the effect of CK2 on the sensitivity of B-ALL cells to rapamycin treatment. Overexpression of CK2 $\alpha$ via retroviral transduction resulted in reduced sensitivity to rapamycin-induced cytotoxicity in B-ALL cells (Fig. 5c). Correspondingly, knockdown of $\mathrm{CK} 2 \alpha$ with shRNA resulted in an increased cytotoxic effect of rapamycin treatment in B-ALL (Fig. 5d).

Overall, the presented data demonstrate that the cytotoxic effects of rapamycin are regulated by CK2 and IKAROS expression. The data also suggest that reduced CK2 activity and/or increased IKAROS function increases the therapeutic effect of rapamycin on B-ALL cells.

\section{The CK2 inhibitor, CX-4945, synergizes with rapamycin in the treatment of B-ALL cells}

Because the data presented in Fig. 5 demonstrate that inhibition of CK2 increases the cytotoxic effects of rapamycin on B-ALL, we tested whether the combination of CK2 inhibitor and rapamycin exert synergistic therapeutic effects on B-ALL cells. We used the CK2 inhibitor, CX4945 [46], that is currently being tested in a Phase I trial [47], and compared the therapeutic effect of CX-4945 and rapamycin combination therapy vs. single-drug treatment, in vitro, on two different human B-ALL cell lines, Nalm6 and 697. Drug response and synergy analyses show that the combination of CX-4945 and rapamycin, given at doses that are achievable in patient serum, produced synergistic cytotoxic effects in both Nalm6 (Fig. 6a) and 697 (Fig. 6b) cell lines.

Combination treatment with CX-4945 and rapamycin, induced increased apoptosis of Nalm6 B-ALL 
Fig. 6 Synergistic effects of CX-4945 with rapamycin on cellular proliferation and apoptosis in B-ALL cells. a-b Effects (left panels) and synergistic analysis (right panels) of rapamycin (black line) and the combination of rapamycin and CX-4945 (red line) on proliferation of (a) Nalm6 cells and (b) 697 cells. Cells were treated with the indicated drugs for 2 days. Cellular proliferation was measured by WST-1 assay. Synergistic analysis was performed using Calcusyn, $Y$ axis is the combination index (CI) value. CI value is: $0.85-1.15$, additive effect, $0.7-0.85$, moderately synergistic; $<0.7$, very synergistic effect (c) Effect of CX-4945 $(4 \mu \mathrm{M})$, rapamycin $(10-20 \mu \mathrm{M})$, and the combination of CX-4945 (4 $\mu \mathrm{M})$ plus rapamycin $(10-20 \mu \mathrm{M})$ on apoptosis in Nalm6 B-ALL cells. Cells were treated for 2 days and stained with 7-AAD and annexin $\mathrm{V}$ for flow cytometry to assess apoptosis. The percentage of cells in the lower right quadrant and upper right quadrant of each flow chart represents the percentage of early apoptotic or late apoptotic cells, respectively, in samples treated with the indicated drugs. ${ }^{*} p<0.05, * * p<0.01, * * * p<$ $0.001, * * * * p<0.0001$.
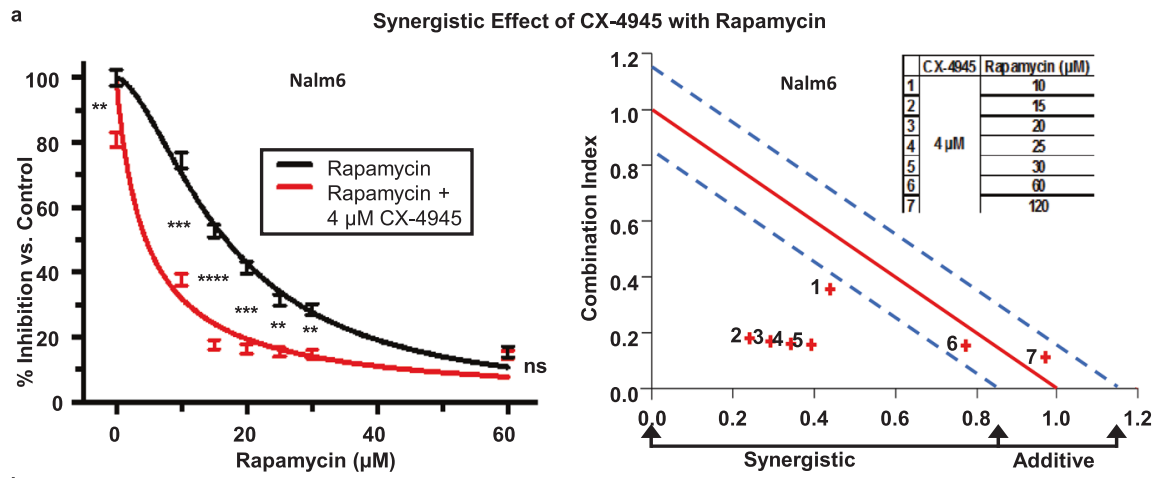

b

Synergistic Effect of CX-4945 with Rapamycin
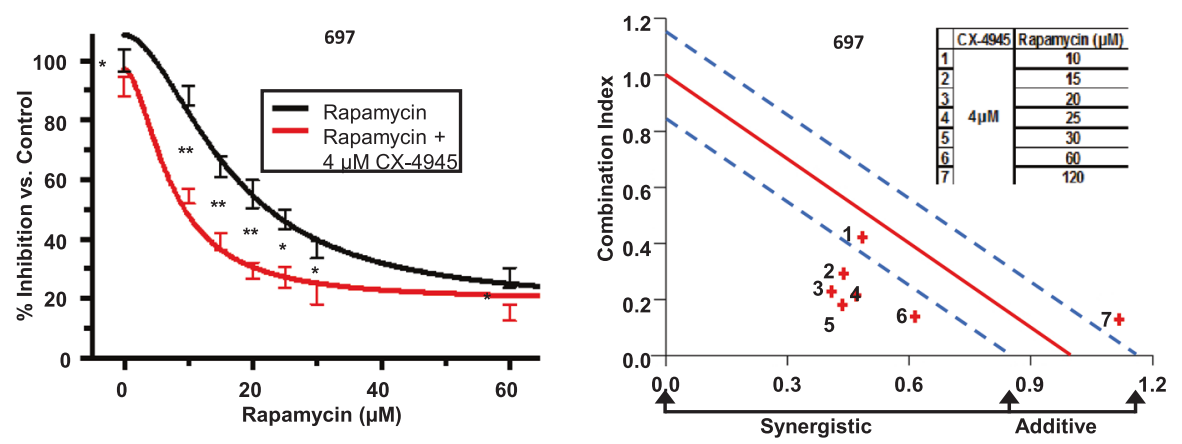

C

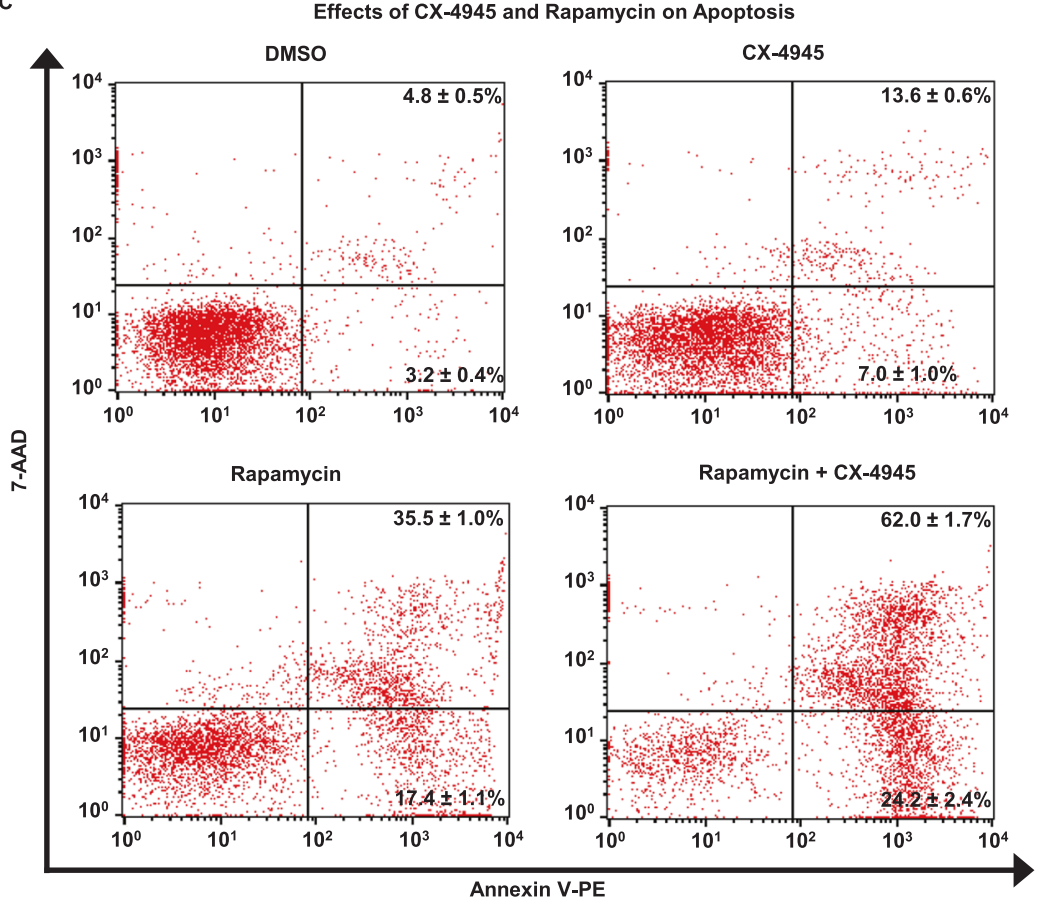

cells as compared to treatment with either drug alone (Fig. 6c).

Overall, these data demonstrate that combination treatment with CX-4945 and rapamycin exerts synergistic cytotoxic activity in B-ALL, and that one mechanism responsible for this synergistic effect involves augmenting the pro-apoptotic effect of rapamycin via CK2 inhibition.
CK2 inhibition augments cytotoxicity of rapamycin in B-ALL patient-derived xenografts from Hispanic/ Latino children with high-risk B-ALL

A frequent feature of high-risk B-ALL in Hispanic/Latino children is increased activity of the $\mathrm{PI} 3 \mathrm{~K} / \mathrm{AKT} / \mathrm{mTOR}$ pathway, which is associated with resistance to 
chemotherapy and poor prognosis $[33,40]$. We hypothesized that targeting the PI3K/AKT/mTOR pathway in this type of B-ALL would exert a strong therapeutic effect in vivo. The in vitro synergistic cytotoxic effects of combination treatment with the CK2 inhibitor, CX-4945, and rapamycin, in B-ALL, suggest that CX-4945 could augment the therapeutic activity of rapamycin against B-ALL in vivo. We tested the therapeutic effect of combination treatment with CX-4945 and rapamycin vs. single-drug therapy in preclinical models of high-risk B-ALL in Hispanic/Latino children. B-ALL was determined to be highrisk based on negative prognostic markers (e.g., deletion of one IKZF1 allele, CRLF2 overexpression etc.) and/or clinical features (Table S1). Following engraftment, mice from each PDX were divided into the following four treatment groups: Group 1: vehicle control, Group 2: CX-4945, Group 3: rapamycin, and Group 4: CX-4945 plus rapamycin combination treatment. Following the completion of treatment, the total live leukemia cells in BM and spleen of mice was determined by flow cytometry.

Results showed that combination treatment with CX-4945 and rapamycin produced a significantly stronger therapeutic effect in all three PDX models, compared to single-drug therapy and/or control (Fig. 7a-c and Fig. S10-12). The total number of viable leukemia cells was severely reduced (3-4fold) in the BM and spleen of the PDX mice treated with combination therapy, compared to mice treated with CX4945 or rapamycin alone. These results demonstrate that the combination of CK2 kinase inhibitor (CX-4945) with rapamycin has a synergistic therapeutic and cytotoxic effect on high-risk B-ALL cells from Hispanic/Latino children, when given as a combination treatment, in vivo.

Laboratory analysis showed that complete blood count, and kidney function tests were not affected by treatment with CX-4945 or rapamycin alone, or in combination (data not shown).

The effect of CX-4945 treatment on MTOR transcription during in vivo treatment was analyzed before cytotoxicity occurred (at days 3 and 7 following the initiation of in vivo treatment with single drugs or combination therapy with CX-4945 and rapamycin, as described above). Data showed that in vivo treatment of primary xenografts with the CK2 inhibitor, CX-4945, in combination with rapamycin, results in the inhibition of mTOR pathway and reduced transcription of the MTOR gene in leukemia cells in both BM and spleen (Fig. S13).

Mice were followed for survival using the Kaplan-Meier method. Results showed that combination treatment with CX-4945 and rapamycin significantly prolongs survival of mice, compared to single-drug treatment (Fig. 7d).

Together, these results demonstrate that combination treatment with the CK2 inhibitor, CX-4945, and rapamycin has a superior therapeutic effect in preclinical models of high-risk B-ALL of Hispanic/Latino children, compared to single-drug treatment. These results suggest that one of the mechanisms through which CK2 inhibition augments the therapeutic effect of rapamycin in vivo includes transcriptional repression of MTOR.

\section{Discussion}

The presented data show that IKAROS functions as a transcriptional repressor of MTOR. Phosphorylation by the oncogenic kinase, CK2, abolishes IKAROS' function as a transcriptional regulator [37, 48-56]. In high-risk B-ALL, the function of IKAROS as an MTOR repressor is impaired by the deletion of one IKZFI allele, or by IKAROS inactivation due to phosphorylation by CK2, which is overexpressed in B-ALL $[5,37]$. Inhibition of CK2 restores IKAROS binding to the MTOR promoter and transcriptional repression of MTOR. Previously published data showed that IKAROS represses the transcription of genes that are essential for the PI3K pathway and that CK2 directly inactivates PTEN through phosphorylation [5, 37, 57]. Results presented in this report reveal a novel mechanism through which CK2 and IKAROS regulate PI3K/AKT/ mTOR signaling in B-ALL-via regulation of MTOR transcription.

mTOR is a kinase that promotes cellular proliferation and survival [58]. Upregulation of the PI3K/AKT/mTOR pathway results in the development of high-risk leukemia that is resistant to chemotherapy $[6,10,59]$. Children of Hispanic/Latino ancestry have an increased frequency of high-risk B-ALL and worse overall survival when compared to other racial/ethnic groups [1]. Molecular epidemiological studies demonstrated increased incidence of translocations resulting in the overexpression of the CRLF2 gene in Hispanic/Latino pediatric patients [2, 33]. Our group reported that the deletion of an IKZFI allele, alone, or in combination with the $C R L F 2$ translocation, is significantly increased in B-ALL of Hispanic/Latino children ${ }^{\text {COMPANION PAPER }}$. CRLF2 acts as an upstream activator of the PI3K/AKT/mTOR pathway [4]. Thus, the presence of $C R L F 2$ translocation and/or IKZF1 deletion makes the increased activity of the PI3K/AKT/mTOR pathway a prominent feature of B-ALL in Hispanic/Latino children, and mTOR an attractive target for treatment of this disease. Our data show that CK2 inhibition with CX-4945 restores IKAROS binding to the MTOR promoter, as well as transcriptional repression of MTOR by IKAROS in high-risk B-ALL cases where there is a deletion of one IKZFI allele. These data provide a rationale for a novel, rationally-designed, mechanism-based, dual approach to target mTOR in high-risk B-ALL in Hispanic/Latino children. This includes the inhibition of mTOR 


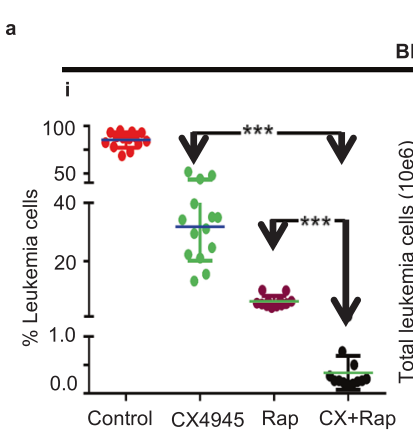

BM
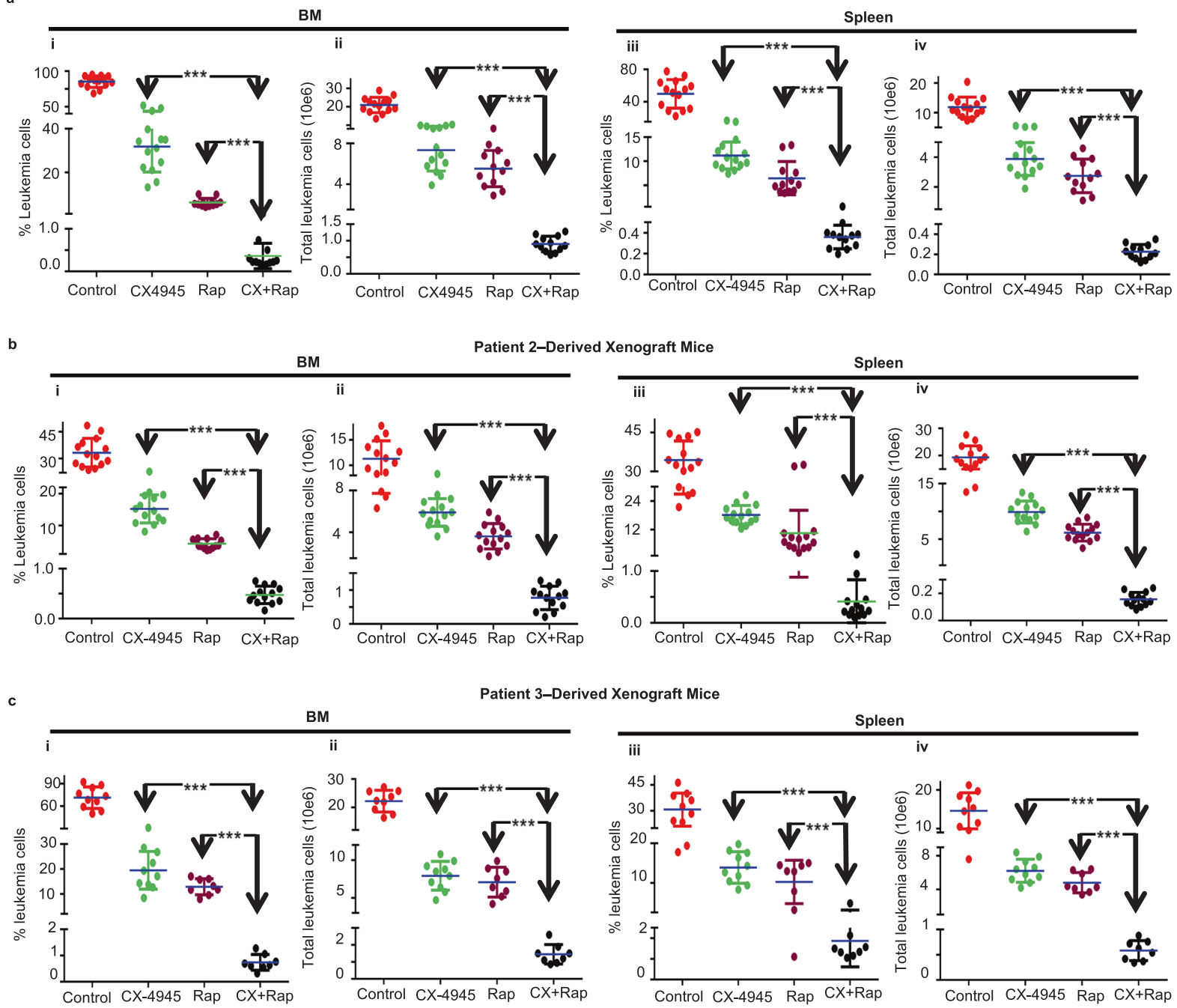

iv

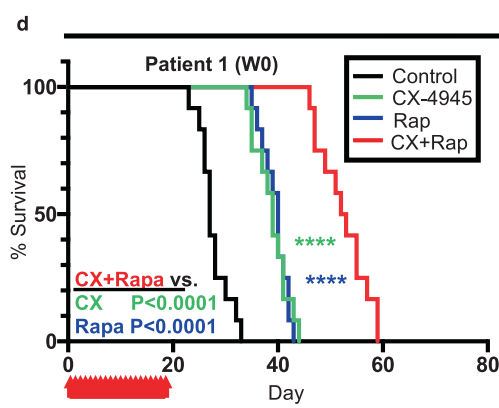

Treatment Effects on PDX Survival
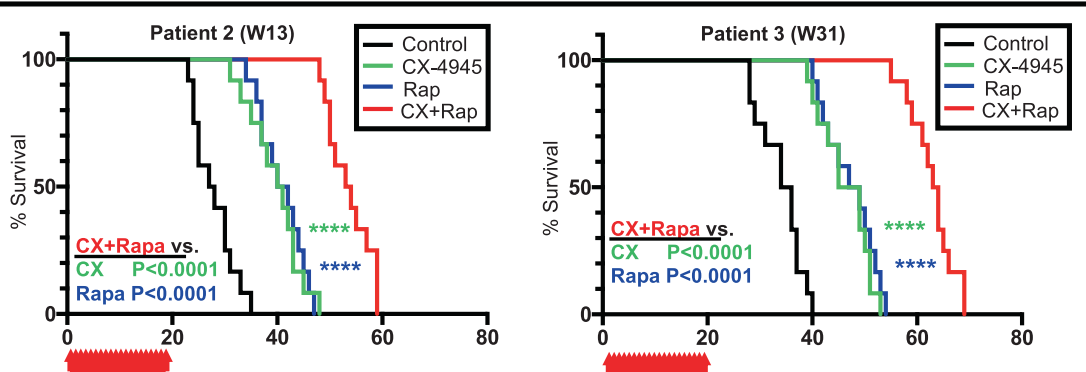

Fig. 7 CK2 inhibition augments cytotoxicity of rapamycin in patient-derived xenografts (PDX) from Hispanic/Latino children with high-risk B-ALL. NRG mice were transplanted via tail vein with primary B-ALL cells from three Hispanic/Latino patients. Once engraftment was established mice were treated with CX-4945 only, rapamycin (Rap) only, CX-4945 + Rap or with vehicle-only control. a-c Following euthanasia, BM and spleen cells were counted, and stained for flow cytometry to detect human B cell markers (CD10 and CD19), mouse CD45, and 7-AAD as a dead cell marker. The percentage of the living B-ALL leukemia cells (i, iii) and total leukemia cells (ii, iv) in BM and spleen were calculated and graphed. The effect of drug treatment was assessed by student's $t$ test. d Patientderived xenografts established with B-ALL from Patients 1-3 were treated for 24 days with CX-4945, rapamycin (Rap) only, CX-4945 plus rapamycin $(\mathrm{CX}+\mathrm{rap})$ or vehicle control and followed for survival. Survival curves were generated using the Kaplan-Meier method and differences in survival were analyzed by Chi-square test. $* * * p<$ $0.001, * * * * p<0.0001$. 


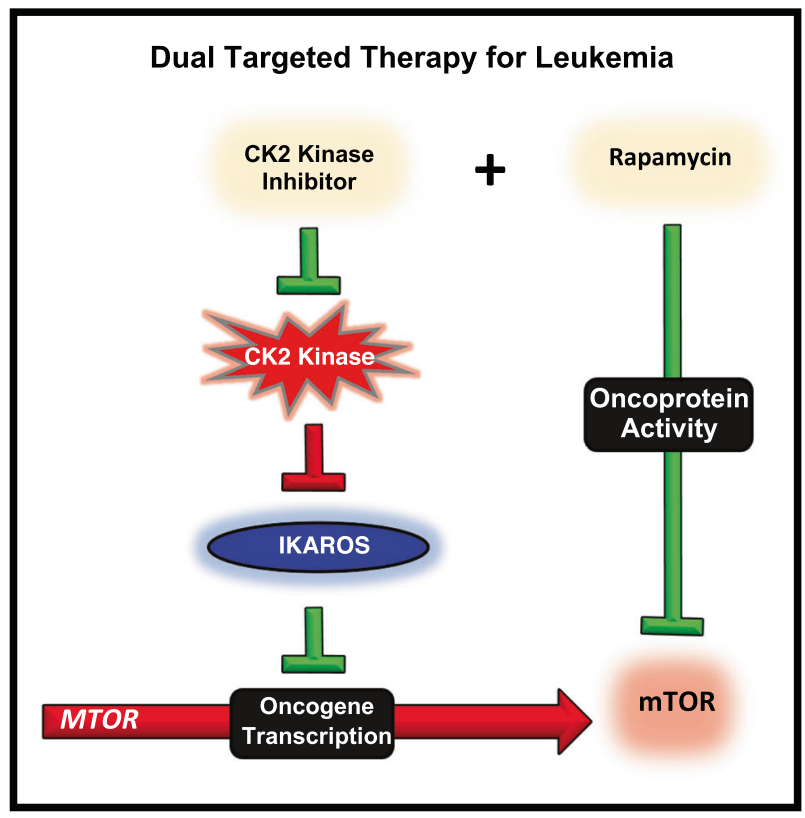

Fig. 8 Model of dual targeted therapy for hematological malignancies. Red arrows and bars indicate pro-oncogenic pathways. Green bars indicated anti-oncogenic pathways.

protein function with rapamycin, in combination with the CK2 inhibitor, CX-4945, which represses MTOR transcription by enhancing IKAROS repressor activity. The dual targeting of mTOR showed a synergistic effect in vitro, and in vivo using three different preclinical models of highrisk B-ALL generated from Hispanic/Latino children (Figs. 6 and 7).

These studies establish a new paradigm for dualtargeting of an oncogenic signaling pathway-targeting both the oncoprotein activity with a direct inhibitor, and the transcription of the gene encoding the oncoprotein (Fig. 8). This dual-targeting approach should overcome chemoresistance due to oncogene overexpression and/or mutation, which often occurs following targeted inhibition. Since the transcriptional regulatory networks of many oncogenes are well-established, this approach opens new possibilities for targeted combination therapies.

In conclusion, our presented data establish the therapeutic efficacy of a novel combination treatment that targets the PI3K/AKT/mTOR signaling pathway in high-risk B-ALL in Hispanic/Latino children. The approach proposed in the study - targeting the transcriptional regulatory network of an oncogene, combined with specific inhibition of the corresponding oncoprotein — can provide a paradigm for similar targeted combination treatments for other hematological malignancies.

Acknowledgements This work was supported by R01CA209829 (KJP and SD); R01CA213912 (SD); F30CA221109 (JLP); R01DK110108 and R01CA204044 (SH); R35GM124820 and R01HG009906 (FY);
NSFC 81770172 (ZG); NCATS- KL2 TR002015 (CG); Hyundai Hope on Wheels Scholar Grants and the Four Diamonds Fund (SD and CG); Alex's Lemonade Stand Foundation, (SD); a St. Baldrick's Foundation Career Development Award and the Rally Foundation (CG); and the Children's Miracle Network (ZCC).

Author contributions SD analyzed and interpreted data, wrote the paper and designed research; CG analyzed and interpreted data and wrote the paper; CS, ZG and YD performed research and wrote the paper; KJP analyzed and interpreted and data, provided patient samples and wrote the paper; YY, ZC, YI, SH and VS analyzed and interpreted data; DD collected data and performed statistical analysis; FY performed statistical analysis; MER provided critical review and assisted in writing the paper; and BT, AS, RG, JLP, YB, TH, ED, SK, MS, MMcGrath, JS, PKD, SI, and DB performed research.

\section{Compliance with ethical standards}

Conflict of interest KJP is CEO and owns stock in Elf Zone, Inc. ZCC is co-founder of Respana Therapeutic, Inc.

Publisher's note Springer Nature remains neutral with regard to jurisdictional claims in published maps and institutional affiliations.

Open Access This article is licensed under a Creative Commons Attribution 4.0 International License, which permits use, sharing, adaptation, distribution and reproduction in any medium or format, as long as you give appropriate credit to the original author(s) and the source, provide a link to the Creative Commons license, and indicate if changes were made. The images or other third party material in this article are included in the article's Creative Commons license, unless indicated otherwise in a credit line to the material. If material is not included in the article's Creative Commons license and your intended use is not permitted by statutory regulation or exceeds the permitted use, you will need to obtain permission directly from the copyright holder. To view a copy of this license, visit http://creativecommons. org/licenses/by/4.0/.

\section{References}

1. American Cancer Society. Cancer Facts and Figures for Hispanics/Latinos 2018-2020. https://www.cancer.org/content/dam/ cancer-org/research/cancer-facts-and-statistics/cancer-facts-andfigures-for-hispanics-and-latinos/cancer-facts-and-figures-forhispanics-and-latinos-2018-2020.pdf.

2. Harvey RC, Mullighan CG, Chen IM, Wharton W, Mikhail FM, Carroll AJ, et al. Rearrangement of CRLF2 is associated with mutation of JAK kinases, alteration of IKZF1, Hispanic/Latino ethnicity, and a poor outcome in pediatric B-progenitor acute lymphoblastic leukemia. Blood. 2010;115(Jul):5312-21.

3. Russell LJ, Capasso M, Vater I, Akasaka T, Bernard OA, Calasanz MJ, et al. Deregulated expression of cytokine receptor gene, CRLF2, is involved in lymphoid transformation in B-cell precursor acute lymphoblastic leukemia. Blood. 2009;114 (Sep):2688-98.

4. Tasian SK, Doral MY, Borowitz MJ, Wood BL, Chen IM, Harvey $\mathrm{RC}$, et al. Aberrant STAT5 and PI3K/mTOR pathway signaling occurs in human CRLF2-rearranged B-precursor acute lymphoblastic leukemia. Blood. 2012;120(Jul):833-42.

5. Gomes AM, Soares MV, Ribeiro P, Caldas J, Povoa V, Martins LR, et al. Adult B-cell acute lymphoblastic leukemia cells display decreased PTEN activity and constitutive hyperactivation of PI3K/ 
Akt pathway despite high PTEN protein levels. Haematologica. 2014;99(Jun):1062-8.

6. Morishita N, Tsukahara $\mathrm{H}$, Chayama K, Ishida T, Washio K, Miyamura T, et al. Activation of Akt is associated with poor prognosis and chemotherapeutic resistance in pediatric Bprecursor acute lymphoblastic leukemia. Pediatr Blood Cancer. 2012;59(Jul):83-89.

7. Kaur A, Sharma S. Mammalian target of rapamycin (mTOR) as a potential therapeutic target in various diseases. Inflammopharmacology. 2017;25(Jun):293-312.

8. Simioni C, Martelli AM, Zauli G, Melloni E, Neri LM. Targeting mTOR in Acute Lymphoblastic Leukemia. Cells. 2019;8:190

9. Ulinska E, Mycko K, Salacinska-Los E, Pastorczak A, Siwicka A, Mlynarski W, et al. Impact of mTOR expression on clinical outcome in paediatric patients with B-cell acute lymphoblastic leukaemia - preliminary report. Contemp Oncol (Pozn). 2016;20:291-6.

10. Nemes K, Sebestyen A, Mark A, Hajdu M, Kenessey I, Sticz T, et al. Mammalian target of rapamycin (mTOR) activity dependent phospho-protein expression in childhood acute lymphoblastic leukemia (ALL). PLoS ONE. 2013;8:e59335.

11. Lo K, Landau NR, Smale ST. LyF-1, a transcriptional regulator that interactswith a novel class of promoters for lymphocytespecific genes. Mollecular Cell Biol. 1991;11:5229-43.

12. Georgopoulos K, Moore DD, Derfler B. Ikaros, an early lymphoid-specific transcription factor and a putative mediator for T cell commitment. Science. 1992;258(Oct):808-12.

13. Winandy S, Wu P, Georgopoulos K. A dominant mutation in the Ikaros gene leads to rapid development of leukemia and lymphoma. Cell. 1995;83(Oct):289-99.

14. Kim J, Sif S, Jones B, Jackson A, Koipally J, Heller E, et al. Ikaros DNA-binding proteins direct formation of chromatin remodeling complexes in lymphocytes. Immunity. 1999;10 (Mar):345-55.

15. Brown KE, Guest SS, Smale ST, Hahm K, Merkenschlager M, Fisher AG. Association of transcriptionally silent genes with Ikaros complexes at centromeric heterochromatin. Cell. 1997;91:845-54.

16. Ding Y, Zhang B, Payne JL, Song C, Ge Z, Gowda C, et al. Ikaros tumor suppressor function includes induction of active enhancers and super-enhancers along with pioneering activity. Leukemia. 2019;33(Nov):2720-31.

17. Gowda C, Song C, Ding Y, Iyer S, Dhanyamraju PK, McGrath M, et al. Cellular signaling and epigenetic regulation of gene expression in leukemia. Adv Biol Regul. 2020;75(Jan):100665.

18. Payne JL, Song C, Ding Y, Dhanyamraju PK, Bamme Y, Schramm JW, et al. Regulation of Small GTPase Rab20 by Ikaros in B-Cell Acute Lymphoblastic Leukemia. Int $\mathrm{J}$ Mol Sci. 2020;21:1718.

19. Mullighan CG, Su X, Zhang J, Radtke I, Phillips LA, Miller CB, et al. Deletion of IKZF1 and prognosis in acute lymphoblastic leukemia. N Engl J Med. 2009;360(Jan):470-80.

20. Kang H, Chen IM, Wilson CS, Bedrick EJ, Harvey RC, Atlas SR, et al. Gene expression classifiers for relapse-free survival and minimal residual disease improve risk classification and outcome prediction in pediatric B-precursor acute lymphoblastic leukemia. Blood. 2010;115(Feb):1394-405.

21. Kuiper RP, Waanders E, van der Velden VH, van Reijmersdal SV, Venkatachalam R, Scheijen B, et al. IKZF1 deletions predict relapse in uniformly treated pediatric precursor B-ALL. Leukemia. 2010;24(Jul):1258-64.

22. van der Veer A, Waanders E, Pieters R, Willemse ME, Van Reijmersdal SV, Russell LJ, et al. Independent prognostic value of BCR-ABL1-like signature and IKZF1 deletion, but not high CRLF2 expression, in children with B-cell precursor ALL. Blood. 2013;122(Oct):2622-9.
23. Martinelli G, Iacobucci I, Storlazzi CT, Vignetti M, Paoloni F, Cilloni D, et al. IKZF1 (Ikaros) deletions in BCR-ABL1-positive acute lymphoblastic leukemia are associated with short diseasefree survival and high rate of cumulative incidence of relapse: a GIMEMA AL WP report. J Clin Oncol. 2009;27(Nov):5202-7.

24. Yokota T, Kanakura Y. Genetic abnormalities associated with acute lymphoblastic leukemia. Cancer Sci. 2016;107(Jun):721-5.

25. Dorge P, Meissner B, Zimmermann M, Moricke A, Schrauder A, Bouquin JP, et al. IKZF1 deletion is an independent predictor of outcome in pediatric acute lymphoblastic leukemia treated according to the ALL-BFM 2000 protocol. Haematologica. 2013;98(Mar):428-32.

26. Olsson L, Castor A, Behrendtz M, Biloglav A, Forestier E, Paulsson K, et al. Deletions of IKZF1 and SPRED1 are associated with poor prognosis in a population-based series of pediatric Bcell precursor acute lymphoblastic leukemia diagnosed between 1992 and 2011. Leukemia. 2014;28(Feb):302-10.

27. Olsson L, Johansson B. Ikaros and leukaemia. Br J Haematol. 2015;169(May):479-91.

28. Marke R, Havinga J, Cloos J, Demkes M, Poelmans G, Yuniati L, et al. Tumor suppressor IKZF1 mediates glucocorticoid resistance in B-cell precursor acute lymphoblastic leukemia. Leukemia. 2016;30(Jul):1599-603.

29. Marke R, van Leeuwen FN, Scheijen B. The many faces of IKZF1 in B-cell precursor acute lymphoblastic leukemia. Haematologica. 2018;103(Apr):565-74.

30. Scheijen B, Boer JM, Marke R, Tijchon E, van Ingen Schenau D, Waanders E, et al. Tumor suppressors BTG1 and IKZF1 cooperate during mouse leukemia development and increase relapse risk in B-cell precursor acute lymphoblastic leukemia patients. Haematologica. 2017;102(Mar):541-51.

31. Roberts KG, Li Y, Payne-Turner D, Harvey RC, Yang YL, Pei D, et al. Targetable kinase-activating lesions in Ph-like acute lymphoblastic leukemia. N Engl J Med. 2014;371(Sep):1005-15.

32. Tran TH, Loh ML. Ph-like acute lymphoblastic leukemia. Hematol Am Soc Hematol Educ Program. 2016;2016 (Dec):561-6.

33. Jain N, Roberts KG, Jabbour E, Patel K, Eterovic AK, Chen K, et al. Ph-like acute lymphoblastic leukemia: a high-risk subtype in adults. Blood. 2017;129(Feb):572-81.

34. Campana D, Janossy G, Bofill M, Trejdosiewicz LK, Ma D, Hoffbrand AV, et al. Human B cell development. I. Phenotypic differences of B lymphocytes in the bone marrow and peripheral lymphoid tissue. J Immunol. 1985;134(Mar):1524-30.

35. Findley HW Jr, Cooper MD, Kim TH, Alvarado C, Ragab AH. Two new acute lymphoblastic leukemia cell lines with early B-cell phenotypes. Blood. 1982;60(Dec):1305-9.

36. Parrish YK, Baez I, Milford TA, Benitez A, Galloway N, Rogerio JW, et al. IL-7 Dependence in human B lymphopoiesis increases during progression of ontogeny from cord blood to bone marrow. J Immunol. 2009;182(Apr):4255-66.

37. Song C, Gowda C, Pan X, Ding Y, Tong Y, Tan BH, et al. Targeting casein kinase II restores Ikaros tumor suppressor activity and demonstrates therapeutic efficacy in high-risk leukemia. Blood. 2015;126(Oct):1813-22.

38. Gurel Z, Ronni T, Ho S, Kuchar J, Payne KJ, Turk CW, et al. Recruitment of ikaros to pericentromeric heterochromatin is regulated by phosphorylation. J Biol Chem. 2008;283 (Mar):8291-300.

39. Popescu M, Gurel Z, Ronni T, Song C, Hung KY, Payne KJ, et al. Ikaros stability and pericentromeric localization are regulated by protein phosphatase 1. J Biol Chem. 2009;284(May):13869-80.

40. Harvey RC, Mullighan CG, Wang X, Dobbin KK, Davidson GS, Bedrick EJ, et al. Identification of novel cluster groups in pediatric high-risk B-precursor acute lymphoblastic leukemia with gene expression profiling: correlation with genome-wide DNA copy 
number alterations, clinical characteristics, and outcome. Blood. 2010;116(Dec):4874-84.

41. Roberts KG, Morin RD, Zhang J, Hirst M, Zhao Y, Su X, et al. Genetic alterations activating kinase and cytokine receptor signaling in high-risk acute lymphoblastic leukemia. Cancer Cell. 2012;22(Aug):153-66.

42. Simioni C, Martelli AM, Zauli G, Vitale M, McCubrey JA, Capitani S, et al. Targeting the phosphatidylinositol 3-kinase/Akt/ mechanistic target of rapamycin signaling pathway in B-lineage acute lymphoblastic leukemia: an update. J Cell Physiol. 2018;233 (Oct):6440-54.

43. Evangelisti C, Chiarini F, McCubrey JA, Martelli AM. Therapeutic Targeting of mTOR in T-Cell Acute Lymphoblastic Leukemia: an Update. Int J Mol Sci. 2018;19:1878.

44. Martelli AM, Evangelisti C, Chappell W, Abrams SL, Basecke J, Stivala F, et al. Targeting the translational apparatus to improve leukemia therapy: roles of the PI3K/PTEN/Akt/mTOR pathway. Leukemia. 2011;25(Jul):1064-79.

45. Martelli AM, Evangelisti C, Follo MY, Ramazzotti G, Fini M, Giardino R, et al. Targeting the phosphatidylinositol 3-kinase/Akt/ mammalian target of rapamycin signaling network in cancer stem cells. Curr Med Chem. 2011;18:2715-26.

46. Siddiqui-Jain A, Drygin D, Streiner N, Chua P, Pierre F, O'Brien SE, et al. CX-4945, an orally bioavailable selective inhibitor of protein kinase CK2, inhibits prosurvival and angiogenic signaling and exhibits antitumor efficacy. Cancer Res. 2010;70 (Dec):10288-98.

47. Buontempo F, McCubrey JA, Orsini E, Ruzzene M, Cappellini A, Lonetti A, et al. Therapeutic targeting of CK2 in acute and chronic leukemias. Leukemia. 2018;32(Jan):1-10.

48. Gowda C, Song C, Kapadia M, Payne JL, Hu T, Ding Y, et al. Regulation of cellular proliferation in acute lymphoblastic leukemia by Casein Kinase II (CK2) and Ikaros. Adv Biol Regul. 2017;63(Jan):71-80.

49. Ge Z, Zhou X, Gu Y, Han Q, Li J, Chen B, et al. Ikaros regulation of the BCL6/BACH2 axis and its clinical relevance in acute lymphoblastic leukemia. Oncotarget. 2017;8(Jan):8022-34.
50. Gowda C, Sachdev M, Muthusami S, Kapadia M, Petrovic-Dovat L, Hartman M, et al. Casein Kinase II (CK2) as a Therapeutic Target for Hematological Malignancies. Curr Pharm Des. 2017;23:95-107.

51. Gowda CS, Song C, Ding Y, Kapadia M, Dovat S. Protein signaling and regulation of gene transcription in leukemia: role of the Casein Kinase II-Ikaros axis. J Investig Med. 2016;64 (Mar):735-9.

52. Ge Z, Gu Y, Han Q, Zhao G, Li M, Li J, et al. Targeting High Dynamin-2 (DNM2) Expression by Restoring Ikaros Function in Acute Lymphoblastic Leukemia. Sci Rep. 2016;6(Nov):38004.

53. Ge Z, Gu Y, Han Q, Sloane J, Ge Q, Gao G, et al. Plant homeodomain finger protein 2 as a novel IKAROS target in acute lymphoblastic leukemia. Epigenomics. 2018;10(Jan):59-69.

54. Ge Z, Han Q, Gu Y, Ge Q, Ma J, Sloane J, et al. Aberrant ARID5B expression and its association with Ikaros dysfunction in acute lymphoblastic leukemia. Oncogenesis. 2018;7(Nov):84.

55. Song C, Ge Z, Ding Y, Tan BH, Desai D, Gowda K, et al. IKAROS and CK2 regulate expression of BCL-XL and chemosensitivity in high-risk B-cell acute lymphoblastic leukemia. Blood. 2020;136:1520-34.

56. Han Q, Ma J, Gu Y, Song H, Kapadia M, Kawasawa YI, et al. RAG1 high expression associated with IKZF1 dysfunction in adult B-cell acute lymphoblastic leukemia. J Cancer. 2019;10:3842-50.

57. Silva A, Yunes JA, Cardoso BA, Martins LR, Jotta PY, Abecasis $\mathrm{M}$, et al. PTEN posttranslational inactivation and hyperactivation of the PI3K/Akt pathway sustain primary $\mathrm{T}$ cell leukemia viability. J Clin Investig. 2008;118(Nov):3762-74.

58. Mirabilii S, Ricciardi MR, Piedimonte M, Gianfelici V, Bianchi MP, Tafuri A. Biological Aspects of mTOR in Leukemia. Int J Mol Sci. 2018;19:2396.

59. Martelli AM, Chiarini F, Evangelisti C, Cappellini A, Buontempo $\mathrm{F}$, Bressanin D, et al. Two hits are better than one: targeting both phosphatidylinositol 3-kinase and mammalian target of rapamycin as a therapeutic strategy for acute leukemia treatment. Oncotarget. 2012;3(Apr):371-94. 